\title{
ARTÍCULOS
}

\section{PATRIMONIO FOTOGRÁFICO EN LAS INSTITUCIONES PÚBLICAS ESPAÑOLAS: MODELOS DE USO Y REPRODUCCIÓN DE DOCUMENTOS}

Juan-Miguel Sánchez-Vigil

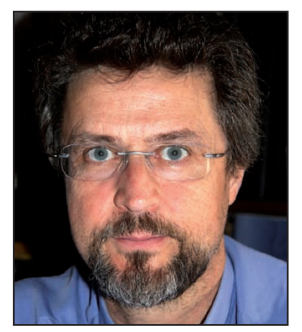

Juan-Miguel Sánchez-Vigil es profesor del Departamento de Biblioteconomía y Documentación de la Universidad Complutense de Madrid, y fotógrafo profesional. Es autor de numerosos libros y artículos relacionados con la fotografía, entre ellos: El documento fotográfico (2006) y Del daguerrotipo a la instamatic (2007). Ha sido comisario de exposiciones fotográficas, las últimas tituladas: Describiendo miradas. La Edad de Plata vista por Alfonso (Ministerio de Cultura, 2010) y Chamberí en Blanco y Negro: 1875-1975 (Ayuntamiento de Madrid, 2011).

Depto. de Biblioteconomía y Documentación, UCM Santísima Trinidad, 37. 28010 Madrid jmvigil@ccinf.ucm.es

\section{Resumen}

Las instituciones públicas españolas han desempeñado una labor extraordinaria en las dos últimas décadas para recuperar, gestionar y difundir el patrimonio fotográfico. Las actuaciones se han llevado a cabo con criterios dispares, poniendo en marcha protocolos de actuación particulares. Se reflexiona sobre varios de estos aspectos, en especial los modelos de uso y reproducción de documentos, y se plantea una serie de propuestas de actuación abiertas al debate.

\section{Palabras clave}

Colecciones fotográficas, Documentación fotográfica, Fotografía, Gestión de patrimonio fotográfico, Patrimonio fotográfico, España, Instituciones públicas, Pautas, Propuestas.

Title: Photographic patrimony of the Spanish public institutions: models for the use and reproduction of the documents

\begin{abstract}
Spanish public institutions have carried out an extraordinary task over the last two decades to recover, manage and promote their photographic patrimony. These actions have been conducted according to diverse criteria and different protocols for action have been adopted. Several of these aspects are studied and, in particular, the models for the use and reproduction of documents. In addition, a series of proposals for action are made and opened for debate.
\end{abstract}

\section{Keywords}

Photographic collections, Photographic documentation, Photography, Management of the photographic patrimony, Photographic patrimony, Public institutions, Guidelines, Proposals.

Sánchez-Vigil, Juan-Miguel. "Patrimonio fotográfico en las instituciones públicas españolas: modelos de uso y reproducción de documentos". El profesional de la información, 2011, julio-agosto, v. 20, n. 4, pp. 371-377.

http://dx.doi.org/10.3145/epi.2011.jul.02

\section{Introducción}

El término "patrimonio cultural" fue asimilado por la Unesco al de "bien cultural" en la década de los sesenta, englobando los bienes tangibles e intangibles (Tugores; Planas, 2006), y entre ellos la fotografía. Su valor es doble en lo que se refiere a los contenidos: por una parte es documento de la realidad y por otra elemento expresivo y estético; en consecuencia, forma parte del patrimonio documental y/o del patrimonio histórico artístico como recoge el artículo 49 del capítulo 1, título VII, de la Ley 16/1985 de 25 de junio del Patrimonio Histórico Español. En dicho artículo se define el documento como "toda expresión en lenguaje natural o convencional, y cualquier otra expresión gráfica, sonora o en imagen recogidas en cualquier tipo de soporte 
material, incluso los soportes informáticos". Los organismos competentes del Estado, comunidades y ayuntamientos han realizado una labor extraordinaria en pro del patrimonio fotográfico y se han puesto en marcha centros encargados de la recuperación, conservación, tratamiento y difusión en los que el esfuerzo y dedicación de los profesionales ha sido y es encomiable. Sin embargo, en algunos aspectos de la gestión se observan modelos de actuación dispares de los que se derivan problemas para los usuarios y que podrían solucionarse con actuaciones conjuntas, es decir con protocolos y normas comunes.

Los estudios sobre la gestión de colecciones y fondos fotográficos en instituciones públicas se iniciaron en 1990 con las jornadas La imatge i la recerca històrica del Ayuntamiento de Girona, abiertas con la ponencia de Vicente-Guitart (1990) sobre los archivos de imágenes en Cataluña, y continuadas bajo la dirección de Joan Boadas. A estos estudios se fueron añadiendo trabajos de varios autores entre los que citamos a Riego et al. (1997), Del-Valle-Gastaminza (1999), Sánchez-Vigil (1999; 2006), Boadas; Casellas; Suquet (2001), Mulet (2007), Robledano (2002; 2007), Iglesias (2008), Letón; Martín-Rizaldos; Martín-García (2008), Balsells (2011), Gato-Gutiérrez (2011) o Rubio-Lara (2011). Otro de los puntos de partida fue el Llibre blanc del patrimoni fotogràfic a Catalunya (1996) en el que participaron el Museu Nacional d'Art de Catalunya (MNAC), el Museu d'Art Contemporani de Barcelona (MACBA), el Arxiu Històric Municipal de Barcelona (AHMB), el Arxiu Nacional de Catalunya $(A N C)$ y el Museu Carnavalet.

Algunos de estos trabajos recogen de manera general la problemática derivada de la gestión que se resume en los planteamientos de Tugores y Planas (2006): falta de recursos para el tratamiento de los fondos, escasa conciencia social del valor patrimonial de la fotografía y dificultad en la recuperación de colecciones. Más allá de estas cuestiones generales que afectan a los centros y que sin duda deben acometerse, hay otras específicas sobre el uso y reproducción de documentos que necesitan de actuaciones para su resolución o para un funcionamiento más dinámico.

Es objeto de este estudio investigar sobre dichos aspectos específicos de la gestión: diversidad de contratos de cesión, política de precios o tasas por reproducción, finalidad de uso del documento, proceso de devolución o destrucción de las copias cedidas, número de ejemplares justificativos de la publicación o difusión, tiempos de respuesta a las peticiones, etc. Ello nos permitirá obtener resultados sobre los diferentes modelos y saber si es necesario un protocolo común.

\section{Metodología}

Además de revisar la bibliografía citada en la introducción, se ha contactado con varios centros públicos de prestigio, de los que nueve han respondido a las consultas sobre los modelos de uso ción? modelo. y reproducción de documentos fotográficos. Cuatro de ellos son estatales y el resto de diferentes Comunidades Autónomas: Biblioteca Nacional de España, Instituto del Patrimonio Cultural de España, Archivo General de la Administración del Estado, Museo Reina Sofía, Biblioteca de Catalunya, Centre de Recerca i Difusió de la Imatge, Filmoteca de Castilla y León, Instituto Valenciano de Arte Moderno, Archivo Municipal de Vitoria y Archivo Regional de la Comunidad de Madrid.

http://www.bne.es

http://www.mcu.es/patrimonio/MC/IPHE

http://www.mcu.es/archivos/MC/AGA

http://www.museoreinasofia.es

http://www.bnc.cat

http://www.girona.cat/sgdap/cat/crdi_portada.php

http://www.jcyl.es

http://www.ivam.es

http://www.vitoria-gasteiz.org

http://www.madrid.org

Se ha estudiado la documentación publicada y difundida en las webs de los centros sobre normas de uso y reproducción, así como los convenios de autorización, con el fin de contrastar sus contenidos. Considerando que la experiencia profesional en el uso de fondos y colecciones de los documentalistas gráficos es fundamental para tratar el tema que nos ocupa, por ser agentes activos y mediadores entre los centros y las empresas o instituciones demandantes, se ha realizado una consulta general (ver cuestionario) sobre las normas de reproducción y uso en centros públicos (no sólo los citados en el artículo). Han colaborado: Manuel Durán (editorial Planeta), Israel Cuchillo (editorial Eutelequia), María Olivera (Ateneo de Madrid y revista Ínsula), Ángeles García-Del-Olmo (colaboradora de la Agencia EFE) y Olimpia Torres (colaboradora de las editoriales Santillana y Espasa).

\section{De la gestión: cuestiones generales}

La gestión de fondos conlleva una actuación institucional relativa a la política de recuperación y al control global de los centros y sus colecciones; es decir tomar decisiones que no dependen de los centros que custodian los fondos sino

Consulta a los profesionales de la documentación gráfica sobre las normas de reproducción y uso de documentos fotográficos en las instituciones públicas

1. ¿Todas las instituciones públicas a las que ha solicitado originales disponen de contratos de cesión, normas por el uso y reproducción, o documentos similares?

Sí $\square$ No $\square$ No contesta

2. ¿Ha encontrado diferencias en las normas de uso y reproducción de documentos en los distintos centros con los que ha contactado?

Sí $\square$ No $\square$ No contesta

3. Señale, entre las que se citan, las diferencias que ha encontrado en los documentos de cesión o uso de fotografías en los centros.

Número de ejemplares a depositar por reproducción de imágenes

Precio de las reproducciones o copias

Falta de información en ciertos temas (derechos, créditos, etc.)

Formas de citar a la institución y/o autor

Cesión de las fotografías para uno o más usos

Criterios de devolución o destrucción de las copias facilitadas

Tiempos de respuesta a la solicitud de copias, forma de pago y entrega de las mismas

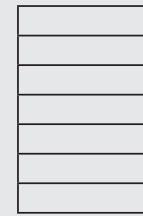

4. ¿Cree que deben unificarse los criterios en un modelo común de documento de cesión o reproduc-

Si $\square$ No $\square$ No contesta

5. Indique cuáles son las razones, a su juicio, por las que deberían unificarse los criterios en el documento

Cuestionario empleado para recabar datos 
de los órganos de gobierno del Estado, las comunidades o ayuntamientos. Las cuestiones dependientes de los órganos de gobierno son fundamentalmente dos: la política de recuperación y el control e información sobre fondos y colecciones. En cuanto a la primera, la política ha cambiado radicalmente en positivo. Prueba de ello es la reciente disputa entre el Ministerio de Cultura y la Generalitat de Catalunya por la adquisición de la obra de Agustí Centelles.

\section{La gestión de los fondos institucionales precisa de políticas de gestión generales}

Uno de los aspectos clave para el usuario es la información sobre las colecciones y sus contenidos, ya que la fotografía se halla dispersa en archivos, bibliotecas, museos, fundaciones o institutos, y no siempre los contenidos están vinculados al centro que los conserva. El documentalista gráfico necesita conocer dónde están los fondos, en qué cantidad y sus principales características, y éste es uno de los problemas con los que se encuentra en su actividad. La Ley del Patrimonio Histórico Español (1985) en su artículo 26 indica que será la Administración del Estado, en colaboración con las demás administraciones competentes, la responsable de confeccionar el inventario general de los bienes muebles del patrimonio histórico español no declarado de interés cultural que tenga relevancia. En este aspecto son fundamentales los inventarios y guías de fondos fotográficos, que tienen origen en el Censo-guía de archivos y colecciones fotográficas de Álava (Aróstegui, 1988), y se continúan en 150 años de fotografía en la Biblioteca Nacional. Guía inventario de los fondos (Kurtz; Ortega, 1989), Inventari d'arxius fotogràfics de Catalunya (Blanch, 1998), Girona. Guia de fons en imatge (Boadas; Casellas, 1999), o la Guia d'arxius, col-leccions i fons fotogràfics i cinematogràfics de les Balears (Aguiló; Mulet, 2004). En relación con los estudios generales sobre la creación de guías o directorios citaremos de nuevo a Mulet (2005) y la reciente propuesta del grupo de profesores de la Universidad Politécnica de Valencia para crear un directorio de fotografía en España basado en el directorio de colecciones digitales Hispana del Ministerio de Cultura (Gato-Gutiérrez et al, 2010).

\section{El documentalista gráfico necesita cono-} cer dónde se encuentran los fondos, en qué cantidad y sus principales características

\section{Cuestiones específicas}

Además de las cuestiones generales hay otras específicas que corresponden directamente a los centros, como son el tratamiento documental y los recursos humanos, y que aun siendo de carácter interno deberían enmarcarse en criterios de acción conjunta. Para el tratamiento documental, cuestión que también supera los límites de este trabajo pero que consideramos necesario comentar, hemos de señalar que cada centro ha habilitado un sistema de trabajo, una metodología para el análisis, si bien con bases de datos de campos similares.

En cuanto a los recursos humanos y técnicos, se consideran aquí a los profesionales relacionados con la fotografía en todos los ámbitos: conservación, documentación y técnica. Sólo los centros dependientes de grandes instituciones estatales o comunitarias, y excepcionalmente algunos organismos locales, cuentan con departamentos de fotografía y especialistas contratados al efecto y capacitados para realizar sus funciones. En muchos casos su implantación es muy reciente, como en el Museu Nacional d'Art de Catalunya (Balsells, 2010). Cabe plantearse cuántos centros públicos con colecciones fotográficas bajo su responsabilidad cuentan con un profesional encargado de gestionar la reproducción de originales, y en tal caso cuáles son los recursos técnicos de que dispone. Por consiguiente, los tiempos de respuesta a la demanda de los usuarios dependen de los recursos humanos y de los medios técnicos, pero también de la gestión al adaptar los recursos a la demanda. De los centros analizados, sólo la Biblioteca de Catalunya indica en el documento de solicitud de reproducción de originales el

\section{Solicitud de reproducción de documentos de la BC}

\section{[nformación del servicio de reprografía]}

Los campos marcados con $\left(^{*}\right)$ son obligatorios para poder tramitar el pedido. Tienes que poner el código de lector o su NIF.

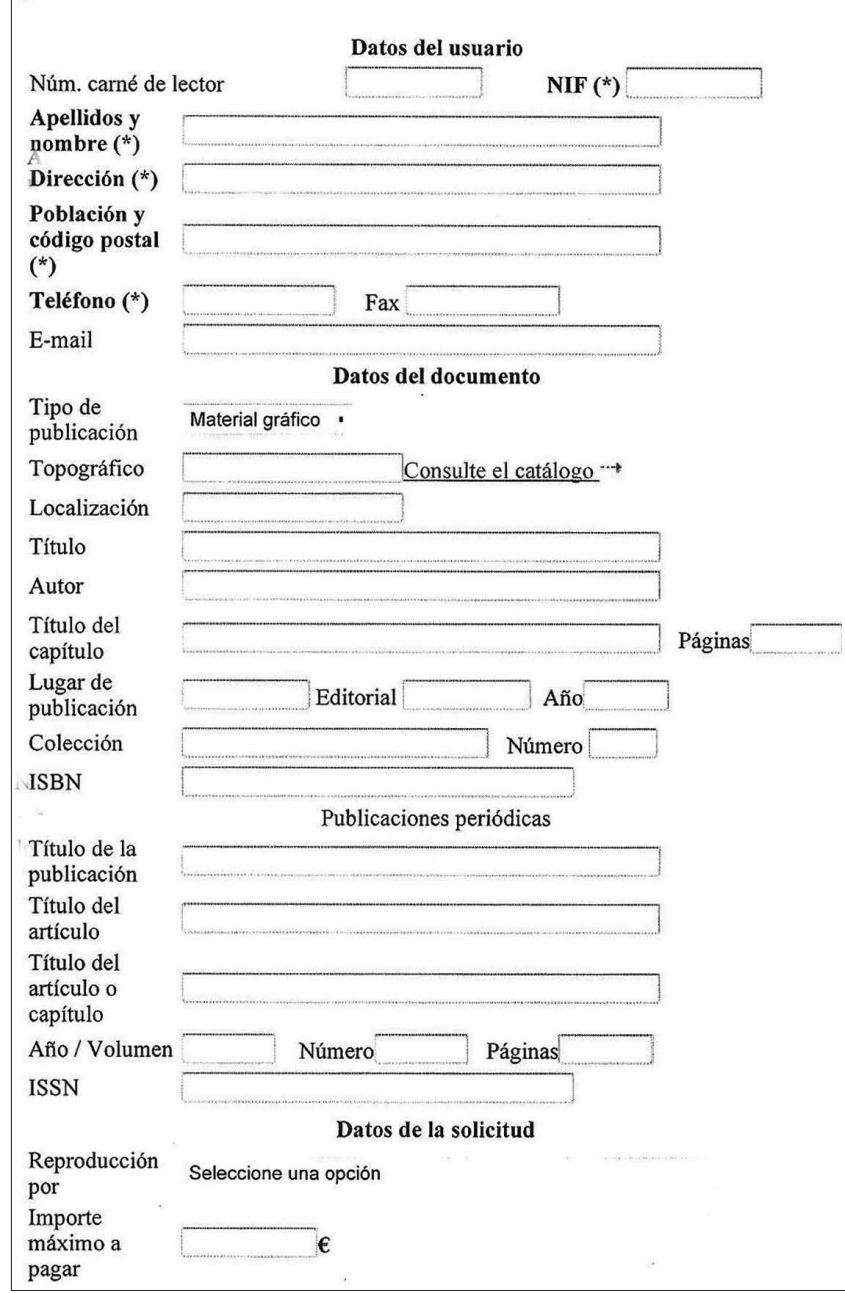

Figura 1. Impreso de solicitud de documentos de la Biblioteca de Catalunya 
Biblioteca Nacional de España. Ministerio de Cultura

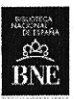

BIBLIOTECA NACIONAL DE ESPAÑA

Formulario de reproducción de documentos

Los campos que aparecen con * son obligatorios En los datos del solicitante es necesario aportar el nombre y apellidos del solicitante o el nombre de la institución.

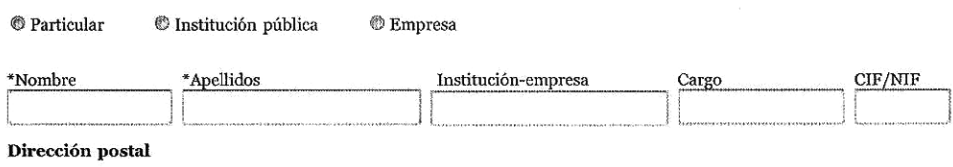

*Calle

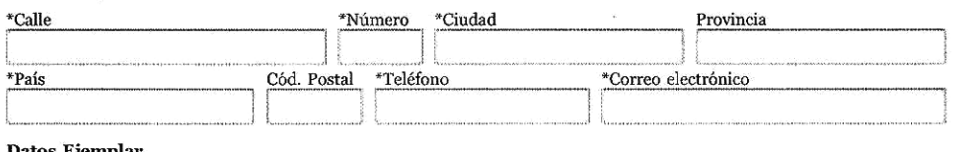

Datos Ejemplar

*Tipo de ejemplar Monografia, dibujo, grabado, fotografía, mapa, partitura

- Prensa y Revistas

- Registro Sonoro o Audiovisual

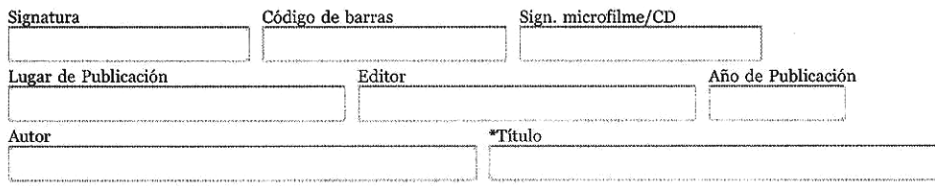

Datos Reproducción

Toda la obra (sólo en el caso de que no se encuentre a la venta)

- Páginas sueltas. Especificar cuáles:

*Tipo de reproducción (consultar precios) *Tipo de uso

Seleccione el tipo de reproducción Seleccione el uso

*Fecha de petición Información complementaria

$12 / 04 / 2011$

國 Declaro conocer y aceptar las normas de reproducción de documentos y me comprometo a no infringir ninguno de los términos expresados en ella

Enviar solicitud

Volver

Figura 2. Formulario de reproducción de documentos de la Biblioteca Nacional de España del Archivo General de la Administración es básicamente de carácter económico, mientras que el del Instituto Valenciano de Arte Moderno (IVAM) detalla los datos de aplicación contemplando la procedencia, los ejemplares por reproducción (tres frente a los ocho del IPCE), devolución de originales y cesión de los derechos correspondientes. El Museo Reina Sofía permite al usuario realizar las copias o reproducciones, por lo que se ahorra prestar este servicio.

El CRDI dispone de varios modelos de documentos relacionados con el tema en estudio (Boadas; Casellas; Suquet, 2001), y en su autorización de reproducción para uso público o copia privada especifica los usos y costos de reproducción, señalando como condiciones generales el respeto de los derechos de autor y la prohibición de cesión a terceros; y como específicas la cesión para un solo uso y una sola edición, la obligación de citar la procedencia, y la entrega de dos ejemplares de la obra donde se incluya el material reproducido. También contempla la posibilidad de que sea el usuario quien realice la reproducción, de acuerdo con las normas de preservación de los documentos.

El Archivo Municipal de Vitoria diseñó un documento de consulta y solicitud de copias de sus fondos que contiene la identificación del usuario, el número de
Sólo los centros dependientes de grandes instituciones cuentan con departamentos de fotografía y especialistas capacitados para realizar sus funciones

tiempo de respuesta: $24-48$ horas para fotocopias y 15 días para fotografía y audiovisuales.

Dentro de las cuestiones específicas nos interesan aquí, por ser objeto de este estudio, los acuerdos de cesión, contratos o formularios de uso que contienen las normas de publicación, ejemplares en depósito, formas de referenciar, citación de los autores o derechos de autor. Los centros seleccionados para el trabajo han elaborado documentos similares pero con información diferente según sus características (figuras 1 a 3).

El Instituto del Patrimonio Cultural de España (IPCE) indica las características técnicas de las copias, la obligación de citar la procedencia, el número de ejemplares a entregar por la publicación (hasta ocho), la finalidad de la petición y la obligatoriedad del pago de la tasa correspondiente. La Biblioteca Nacional de España, la de Catalunya y el Centre de Recerca i Difusió de la Imatge (CRDI) son los únicos centros que fijan precios por reproducción en la web. El documento consultas, el número de imágenes consultadas y el tamaño y soporte en que el usuario desea el original. Se indican como normas a cumplir: uso en el destino citado en la petición, procedencia, prohibición de ceder el original a terceros, de manipulación de la imagen y de generar reproducciones. En un segundo documento, denominado "Convenio de autorización", se repiten las cláusulas más la obligación de depositar un ejemplar de la publicación.

Por tanto, el uso de un mismo documento fotográfico conservado en distintas instituciones plantea al usuario cuestiones o respuestas tan diferentes como la entrega de distinto número de ejemplares, varios modos de citar la procedencia, o tasas diversas para el mismo uso (publicidad, edición, web, comunicación o investigación).

El uso de un mismo documento fotográfico conservado en distintas instituciones plantea al usuario cuestiones o respuestas diferentes

Los precios de reproducción (tabla 1), suelen establecerse por los organismos de los que depende el centro, como ejemplo la Ley de Tasas por autorización para publicar o reproducir microfilm, películas, fotografías o diapositivas aprobada por el 


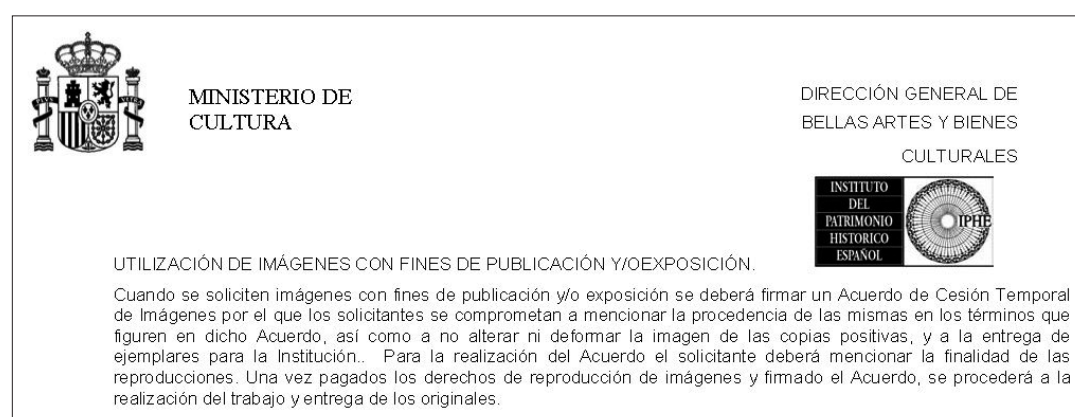

\section{ACUERDO DE CESIÓN TEMPORAL DE IMÁGENES}

En Madrid, a

\section{RE U N I D O S}

DE UNA PARTE, D... Subdirector General del Instituto del Patrimonio Histórico Español, de la Dirección General de Bellas Artes y Bienes Culturales, Ministerio de Cultura ( en adelante CEDENTE),

DE OTRA PARTE, D... (en adelante CESIONARIO),

\section{E X P O N EN}

I. Que para llevar a cabo se necesita determinado material gráfico.

II. Que el Ministerio de Cultura es propietario de la Fototeca del Patrimonio Histórico, dónde se encuentra documentación relacionada con el tema al que se hace referencia en el punto anterior.

$\mathrm{Y}$ en su virtud ambas partes se reconocen capacidad para suscribir el presente ACUERDO DE CESION TEMPORAL DE REPRODUCCION ( YDISTRIBUCIÓN, en su caso) DE MATERIAL GRAFICO, en base a las siguientes

\section{ES T I P U L A C I ONES}

PRIMERA: EI CEDENTE autoriza al CESIONARIO las reproducciones de las siguientes imágenes: / del ANEXO:

SEGUNDA: El presente acuerdo se realiza únicamente para , a que se hace referencia en el punto $I$

TERCERA: En dicha publicación, / presentación, deberá aparecer reflejada la procedencia de la imagen en los siguientes términos:

Archivo ...... IPHE. Ministerio de Cultura

CUARTA: EI CESIONARIO entregará al CEDENTE cinco (5) ejemplares de la publicación.

QUINTA: El cesionario hará efectiva la cantidad estipulada al efecto.

SEXTA: Para todas las dudas e incidencias que puedan surgir de la interpretación y aplicación del presente Acuerdo serán competentes los tribunales y juzgados de Madrid capital, con renuncia expresa a cualquier otro fuero que pudiera corresponder.

$Y$ en prueba de conformidad firman el presente Acuerdo, que se extiende por duplicado, en el lugar y la fecha indicado ut supra.

EL CEDENTE, EL CESIONARIO, DNI: DNI: Pasaporte:

Figura 3. Acuerdo de cesión temporal de imágenes del Instituto del Patrimonio Histórico Español
Consejo de la Generalitat de Catalunya en el artículo 115 del Decreto Legislativo $1 / 2005$ de 25 de febrero. Prácticamente todas las instituciones informan sobre este tema en detalle con gran variedad de tasas, desde los 3 euros del AGA por una copia para uso general, hasta los 851,90 euros del IVAM por aplicación a publicidad. El CRDI presenta 36 tarifas diferentes dentro de ocho apartados generales (prensa, productos audiovisuales, edición, multimedia, publicidad, proyecciones y audiciones, artículos de papelería y otros usos).

La Filmoteca de Castilla y León, dependiente de la Consejería de Cultura y Turismo de esa Comunidad, tiene como norma no comprar documentos (sólo admite donaciones) y establece que cualquier cesión o reproducción incumbe al depositante, propietario de los originales a todos los efectos. En consecuencia es éste quien autoriza la reproducción y quien decide si la cesión es o no gratuita. El centro, en este caso, establece una mínima cantidad por la reproducción.

La diversidad es tanta que el Archivo Regional de la Comunidad de Madrid facilita temporalmente copias de los originales de algunas de sus colecciones (por ej., la de Martín Santos-Yubero) al precio simbólico de 1 euro.

\section{Valoración de los usuarios profesionales}

La valoración de los profesionales de la documentación gráfica citados en la metodología se refiere a su experiencia en numerosos centros públicos (no exclusivamente a los que figuran en el artículo). Todos ellos coinciden en varios aspectos:

\begin{tabular}{|l|c|c|c|c|c|}
\hline \multicolumn{1}{|c|}{ Centro } & $\begin{array}{c}\text { Tasa } \\
\text { general }\end{array}$ & $\begin{array}{c}\text { Divulgativo } \\
\text { particular }\end{array}$ & Prensa Edición & Publicidad & Web \\
\hline Archivo General de la Administración del Estado (AGA) & $3-21$ & - & - & - & - \\
\hline Instituto del Patrimonio Cultural de España (IPCE) & $6-12$ & - & - & - & - \\
\hline Instituto Valenciano de Arte Moderno (IVAM) & 10,23 & 102,24 & 170,39 & 851,90 & - \\
\hline Biblioteca Nacional de España (BNE) & $3-5$ & 76,29 & 25,43 & 109,86 & 25,43 \\
\hline Biblioteca de Catalunya (BC) & $8-25$ & 60 & 20 & 60 & - \\
\hline Centre de Recerca i Difusió de la Imatge (CDRI) & 44,05 & - & $\begin{array}{c}\text { Prensa: } 44-119 \\
\text { Edición: 83-137 }\end{array}$ & $83-167$ & 167 \\
\hline Filmoteca de Castilla y León & 4,21 & 4,21 & 4,21 & 4,21 & 4,21 \\
\hline Archivo Municipal de Vitoria (1) & 1,5 & 1,5 & 1,5 & 1,5 & 1,5 \\
\hline Archivo Regional de la Comunidad de Madrid & 1 & 1 & 1 & 1 & 1 \\
\hline
\end{tabular}

Tabla 1. Tasas de las reproducciones fotográficas según el uso (en euros)

(1) Los precios son de reproducciones digitales sobre CD. Las copias en papel de laboratorio en blanco y negro oscilan entre los 2,75 y los 30 euros, y las copias digitales sobre papel entre 1,06 y 4,59. 


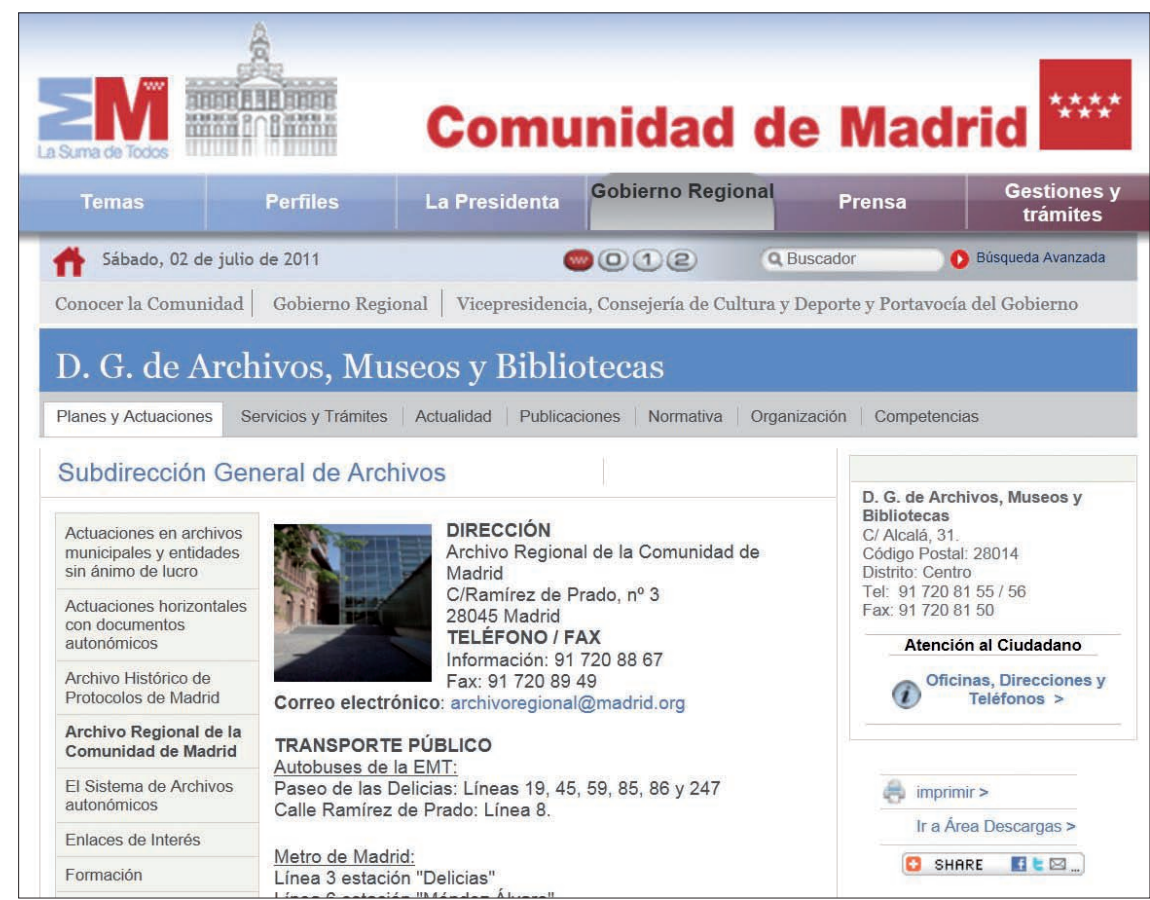

http://www.madrid.org

- la mayoría de los centros disponen de un modelo de documento propio sobre el uso y reproducción de fotografías;

- los criterios aplicados por los centros son diferentes en casi todos los casos;

- existe una evidente disparidad de precios para los mismos usos;

- no se indican los tiempos de entrega de las copias y cuando se indican son sólo referencia;

- el número de ejemplares a entregar de la obra publicada por usos similares es diferente.

Dos de los consultados señalan que la información en temas como los derechos y las formas de citación de autores y centros (créditos) es escasa, y sólo a uno de los profesionales le preocupa si la cesión del documento es para uno o más usos. Asimismo todos advierten que generalmente no se indican los criterios de destrucción de copias digitales o devolución de las fotoquímicas. Finalmente todos abogan por la unificación de criterios en un documento común, justificado por estas ventajas: ahorro de tiempo en la gestión profesional, mejora de la relación personal o profesional con la empresa o institución para la que trabajan o colaboran, mayor facilidad para elaborar y ajustar los presupuestos de los proyectos, aumento de la información sobre cuestiones relativas a derechos de autor y también sobre el uso de las fotografías en temas específicos (se indica como ejemplo la posible repetición de un mismo documento).

\section{Propuestas de actuación}

De todo lo expuesto resulta una serie de cuestiones sobre la gestión que conviene revisar con el fin de alcanzar la normalización, con los criterios comunes o los matices necesarios que permitan responder a la demanda. Con carácter general, en cuanto a las políticas de recuperación de colecciones los órganos de gobierno deberían elaborar censos o registros de colecciones susceptibles de ser recuperadas, una bolsa de colecciones con las características de los con- tenidos y las acciones a realizar a corto, medio o largo plazo para evitar su pérdida o deterioro.

Es fundamental el apoyo a los centros para la inversión en programas de tratamiento de los documentos y su difusión. Sobre el control e información de fondos y colecciones se plantean aquí dos cuestiones: conocer los fondos de cada una de las instituciones públicas y generar o estructurar los medios o sistemas para que se conozcan. La tecnología permite actualmente no sólo conocer sino también acceder a las colecciones, si bien de manera parcial por falta de inventarios generales. Es por tanto necesario realizar un directorio general de centros y colecciones de toda España con el detalle de sus características.

Respecto a los recursos humanos y técnicos deben crearse y/o reactivarse, en su caso, los departamentos de fotografía responsables de aspectos técnicos. Al frente de los mismos deberán figurar profesionales cualificados para responder a las peticiones de los usuarios, y su función será el tratamiento del original y la normalización de las características técnicas de la reproducción o copia de la imagen. Ello redundaría en los tiempos de respuesta, un aspecto que los documentalistas gráficos valoran extraordinariamente. Asimismo, como resultado de lo expuesto, deberían aplicarse precios similares por la reproducción de originales y establecer criterios comunes en las cuestiones planteadas. Gran parte de estos problemas podría resolverse con dos actuaciones concretas:

a) Creación de un organismo estatal (Centro Nacional de Documentación Fotográfica) que coordine el funcionamiento de los autonómicos y locales, responsable de analizar la problemática tanto de los centros como de los usuarios (documentalistas gráficos y otros) y trabajar en los temas comentados. Una de sus funciones sería elaborar el inventario, directorio y guía de fondos y colecciones de España, dependiendo del órgano competente (Ministerio de Cultura). Su existencia se justifica por la necesidad de conocer los fondos y colecciones, y por el control global de los originales con un objetivo claro: la preservación, la información y la coordinación entre instituciones.

b)Diseño de un documento único de acuerdo de cesión de imágenes para su uso y reproducción, consensuado por todos los implicados y homologado en todo el Estado español. Se fijaría así una normativa al tiempo que un modelo informativo. Su existencia se justifica como respuesta común a los usuarios, especialmente a los profesionales de la documentación gráfica.

\section{Conclusiones}

1. Se desconoce el total de centros públicos españoles con fondos fotográficos. Asimismo se desconocen las colecciones y originales debido a su dispersión. 
2. La creación de un Centro Nacional de Documentación Fotográfica o bien un organismo similar permitiría realizar un directorio de centros y fondos en todo el Estado, haciendo visibles las colecciones invisibles y fomentando la relación, mediante eventos, de los profesionales encargados de la gestión en las instituciones públicas.

3. Es necesario normalizar los protocolos de actuación (acuerdos de cesión o formularios de reproducción) generando un documento único que contenga información sobre el uso y reproducción de los originales fotográficos.

4. El documento único permitirá conocer el material utilizado, el número de usos, las aplicaciones de los originales, los autores de las fotografías consultadas, las colecciones con mayor demanda, los precios aplicados, los ejemplares a depositar en cada caso, y otras informaciones que se estimen y que resulten de interés para valorar y mejorar la calidad del servicio.

5. La política de acción común facilita la labor de los profesionales de los centros y de los usuarios. Una hoja de ruta permitiría seguir las pautas para alcanzar los objetivos generales y específicos.

\section{Bibliografía}

Aguiló, Catalina; Mulet, Maria-Josep. Guía d'arxius, colleccions i fons fotogràfics i cinematogràfics de les Balears, 1840-1967. Palma: Fundación Sa Nostra, 2004. ISBN: 9788496031388 .

Aróstegui, Pilar. Censo guía de archivos y colecciones fotográficas en Álava. Vitoria: Gobierno Vasco, 1988.

Balsells, David. "El departament de fotografia del Museu Nacional d'Art de Catalunya (MNAC), actuació y contingut". En: Imatge i recerca. $11^{\text {es }}$ Jornades Antoni Varés. Girona: Ajuntament, 2011, pp. 65-70.

Blanch, Albert. Inventari d'arxius fotogràfics de Catalunya. Barcelona: Azimut, 1998. DL: B-25.624-98.

http://www.ultrafox.com/ct/iafc/afmain.htm

Boadas, Joan; Casellas, Lluís-Esteve. Girona. Guia de fons en imatge. Girona: Ajuntament, 1999. ISBN: 8486837790

Boadas, Joan; Casellas, Lluís-Esteve; Suquet, Maria-Àngels. Manual para la gestión de fondos y colecciones fotográficas. Girona: CCG, 2001. ISBN: 8495483114.

Del-Valle-Gastaminza, Félix et al. Manual de documentación fotográfica. Madrid: Síntesis, 1999. ISBN: 8477386897

Gato-Gutiérrez, Mario; Aleixandre, Rafael; Benlloch, Pep; Ferrer, Antonia; Maynés, Pau; Millán, Luis; Peset, Fernanda. "Colecciones de fotografía en España: propuesta del directorio fotográfico en España (DeFoto)". En: Imatge i recerca. $11^{\text {es }}$ Jornades Antoni Varés. Girona: Ajuntament, 2011, pp. 137-139.

http://www.girona.cat/sgdap/docs/r25pw6vdefoto-upv.pdf

Iglesias-Franch, David. La fotografía digital en los archivos. Qué es y cómo se trata. Gijón: Trea, 2008. ISBN: 978849704 3779
Kurtz, Gerardo; Ortega, Isabel. 150 años de fotografía en la Biblioteca Nacional. Guía inventario de los fondos. Madrid: Ministerio de Cultura, 1989. ISBN: 8486022320

Letón-Ruiz, Raquel; Martín-Rizaldos, Silvia; Martín-García, Leticia. "Pautas y actuaciones para la gestión integral de fondos y colecciones fotográficas". En: Imatge i recerca. $10^{\text {es }}$ Jornades Antoni Varés. Girona: Ajuntament, 2008, pp. 95-97.

http://www.girona.cat/sgdap/docs/htau3p3leton.pdf

Ley 16/1985, de 25 de junio, del Patrimonio Histórico Español. Título VII. Del patrimonio documental y bibliográfico y de los archivos, bibliotecas y museos. Cap. 1. Del patrimonio documental y bibliográfico. Art. 49.

Llibre blanc del patrimoni fotogràfic a Catalunya. Barcelona: Generalitat de Catalunya, 1996. ISBN: 84-39339-84-4.

Mulet, Maria-Josep. "La creación de guías de archivos fotográficos". En: Actas del Primer congreso de historia de la fotografía. Zarautz: Photomuseum, 2005, pp. 33-43. ISBN: 8481480266 .

Mulet, Maria-Josep. "El acceso a la información sobre patrimonio fotográfico en el Estado español". Latente: revista de historia y estética del audiovisual. La Laguna: Servicio de Publicación de la Universidad de La Laguna, 2007, n. 5, pp. 57-72.

Riego, Bernardo; Alonso-Laza, Manuela; Muñoz-Benavente, Teresa; Argerich, Isabel; Fuentes-De-Cêa, Ángel. Manual para el uso de archivos fotográficos. Madrid: Ministerio de Cultura, 1997. ISBN: 8492324007

Robledano-Arillo, Jesús. "Estándares para la descripción de fotografía". D’arxius, 2007, diciembre, n. 6, pp. 149-188.

Robledano-Arillo, Jesús; Moreiro-González, José-Antonio. "La recuperación documental de la imagen fotográfica: perspectiva tecnológica y documental". En: Primeras Jornadas imagen, cultura y tecnología. Madrid: Archiviana, 2002. ISBN: 8495933063

http://e-archivo.uc3m.es/bitstream/10016/8951/1/recupe racion_ICT_2002.pdf

Rubio-Lara, Teresa. "Laboratorio de cartografía e imagen digital del Instituto Andaluz de Patrimonio Histórico". En:

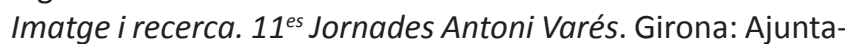
ment, 2011, pp. 137-139.

http://www.girona.cat/sgdap/docs/icc47gdrubio-teresa.pdf

Sánchez-Vigil, Juan-Miguel. El documento fotográfico. Historia, usos y aplicaciones. Gijón: Trea, 2006. ISBN: 849704 2239

Sánchez-Vigil, Juan-Miguel. El universo de la fotografía. Prensa, edición, documentación. Madrid: Espasa, 1999. ISBN: 8423991954

Tugores, Francesca; Planas, Rosa. Introducción al patrimonio cultural. Gijón: Trea, 2006. ISBN: 8497042425

Vicente-Guitart, Carles. "Els arxius d'imatges a Catalunya: balanç i perspectives". En: Imatge i recerca. 1es Jornades Antoni Varés. Girona: Ajuntament, 1990, pp. 9-25.

http://www.girona.cat/sgdap/docs/quuyyq/carles\%20vicen te\%20i\%20guitart.pdf 